\title{
Distinguishing the impacts of ozone and ozone-depleting substances on the recent increase in Antarctic surface mass balance
}

\author{
Rei Chemke $^{1,2}$, Michael Previdi ${ }^{3}$, Mark R. England ${ }^{4,5}$, and Lorenzo M. Polvani ${ }^{2,3}$ \\ ${ }^{1}$ Department of Earth and Planetary Sciences, Weizmann Institute of Science, Rehovot, Israel \\ ${ }^{2}$ Department of Applied Physics and Applied Mathematics, Columbia University, New York, NY, USA \\ ${ }^{3}$ Lamont-Doherty Earth Observatory, Columbia University, Palisades, NY, USA \\ ${ }^{4}$ Department of Climate, Atmospheric Science, and Physical Oceanography, Scripps Institution of Oceanography, \\ UCSD, La Jolla, CA, USA \\ ${ }^{5}$ Department of Physics and Physical Oceanography, University of North Carolina Wilmington, NC, USA
}

Correspondence: Rei Chemke (rei.chemke@weizmann.ac.il)

Received: 13 June 2020 - Discussion started: 25 June 2020

Revised: 29 September 2020 - Accepted: 7 October 2020 - Published: 19 November 2020

\begin{abstract}
The Antarctic surface mass balance (SMB) has global climatic impacts through its effects on global sealevel rise. The forced increase in Antarctic SMB over the second half of the 20th century was argued to stem from multiple forcing agents, including ozone and ozone-depleting substances (ODSs). Here we use ensembles of fixed-forcing model simulations to quantify and contrast the contributions of stratospheric ozone, tropospheric ozone and ODSs to increases in the Antarctic SMB. We show that ODSs and stratospheric ozone make comparable contributions and together account for $44 \%$ of the increase in the annual mean Antarctic SMB over the second half of the 20th century. In contrast, tropospheric ozone has an insignificant impact on the SMB increase. A large portion of the annual mean SMB increase occurs during austral summer, when stratospheric ozone is found to account for $63 \%$ of the increase. Furthermore, we demonstrate that stratospheric ozone increases the SMB by enhancing the meridional mean and eddy flows towards the continent, thus converging more water vapor over the Antarctic.
\end{abstract}

\section{Introduction}

Being the largest freshwater reservoir on Earth, the Antarctic ice sheet is potentially the largest contributor to future global sea-level rise (IPCC, 2013; Fretwell et al., 2013). By 2100, the projected loss of Antarctic land-ice due to dynam- ical processes (i.e., the flow of the ice sheet) will increase sea level by up to $185 \mathrm{~mm}$ (IPCC, 2013; Golledge, 2020). In contrast, the projected increase in Antarctic surface mass balance (SMB; i.e., the larger increase in precipitation vs. evaporation/sublimation; e.g., see Agosta et al., 2019) will reduce this sea level rise by $20-80 \mathrm{~mm}$ (Krinner et al., 2007; Uotila et al., 2007; Ligtenberg et al., 2013; Frieler et al., 2015; Previdi and Polvani, 2016; Palerme et al., 2017). Over recent decades, however, only the dynamical mass loss due to the acceleration of outlet glaciers has been documented (Rignot et al., 2004; Shepherd et al., 2012; Velicogna et al., 2014; Wouters et al., 2015; Rignot et al., 2019); the Antarctic SMB has exhibited insignificant trends (Monaghan et al., 2006a,b; Lenaerts et al., 2012) and thus has yet to mitigate sea-level rise. Although climate models do simulate an increase in Antarctic SMB over recent decades in response to the external forcings (Krinner et al., 2007; Monaghan et al., 2008; Palerme et al., 2017; Previdi and Polvani, 2017), such an increase has been obscured by the large climate variability (Previdi and Polvani, 2016), resulting in insignificant observed Antarctic SMB trends (Frezzotti et al., 2013).

Similar to most late 20th century forced changes in the Southern Hemisphere (Polvani et al., 2011b), the modeled increase in Antarctic SMB, and incursion of dust particles into the Antarctic continent (Cataldo et al., 2013), has also been attributed to anthropogenic emissions. In particular, two recent studies have argued for the importance of increases in the emissions of ozone-depleting substances (ODSs) (Prev- 
idi and Polvani, 2017) and in stratospheric ozone depletion (Lenaerts et al., 2018) for Antarctic SMB. However, neither study cleanly isolated the effects of these forcing agents: Previdi and Polvani (2017) did not separate the effects of ODSs from stratospheric ozone, while Lenaerts et al. (2018) did not separate the effects of stratospheric from tropospheric ozone. This, together with the fact that different seasons were analyzed in these two studies, has prevented a clear attribution of the forced SMB increase. In addition, a quantitative analysis of the mechanism underlying the forced increase in SMB has not been conducted to date.

The aim of this paper is thus to elucidate which forcing agents related to ozone have mostly contributed to the forced increase in Antarctic SMB over the second half of the 20th century and to quantitatively analyze the underlying mechanisms. This is done using ensembles of fixed-forcing simulations which allow us to disentangle the impacts of stratospheric ozone depletion, tropospheric ozone changes and ODS emissions on Antarctic SMB trends.

\section{Methods}

We analyze four ensembles of model simulations using the Community Earth System Model (CESM1) (Hurrell et al., 2013): each ensemble is forced with slightly different agents. We use this CMIP5-class model as previous work showed that the CESM captures the spatial patterns of climatological mean Antarctic SMB, and its variability, from ice cores and reanalysis (Lenaerts et al., 2018). Furthermore, the CESM well captures the climate response in the Southern Hemisphere to ozone depletion (England et al., 2016; Landrum et al., 2017). This provide us confidence in using the CESM to investigate SMB changes under forced ozone changes.

The first ensemble consists of 10 members, which were randomly picked from the 40-member large ensemble (LENS) described in Kay et al. (2015). Each member is forced, from 1920 to 2005, with all known natural and anthropogenic forcings, following the historical specifications of the Climate Modeling Intercomparison Project, Phase 5 (Taylor et al., 2012). While all simulations are subjected to the same forcing, they differ in their initialization: each member is initialized at 1920 with a slightly different air temperature $\left(\mathcal{O} 10^{-14} \mathrm{~K}\right.$, across all grid points), thus allowing us to investigate the climate's transient response to the external forcing in the presence of internal climate variability.

The other three ensembles are identical to the LENS but without time evolution of specific forcing agents: a 10member ensemble with fixed ODS (Fix-ODS; Polvani et al., 2020), a 10-member ensemble with fixed ODS and stratospheric ozone (Fix-ODS\&O3 $3_{\text {strat }}$; Polvani et al., 2020), and an 8-member ensemble with fixed stratospheric and tropospheric ozone (Fix-O3; England et al., 2016; Landrum et al., 2017; Lenaerts et al., 2018). These forcing agents are fixed at 1955 values (pre-ozone hole). Each simulation in the fixed-forcing ensembles is initialized from the corresponding simulation of the LENS at 1950 . Thus, the ensemble mean difference between LENS and Fix-ODS, averaged over 1990-2005, allows one to isolate and quantify the effects of ODSs over the second half of the 20th century. Similarly, the ensemble mean difference between FixODS and Fix-ODS\&O3 $3_{\text {strat }}$ isolates the effects of stratospheric ozone $\left(\mathrm{O}_{\text {strat }}\right)$. Finally, subtracting the effects of stratospheric ozone from the ensemble mean difference between LENS and Fix-O3 isolates the effects of tropospheric ozone $\left(\mathrm{O}_{\text {trop }}\right)$. This procedure assumes that the forcings are linearly additive, and it should be clear that the model runs analyzed here were not originally designed for this study; rather, we are here simply exploiting these "ensembles of opportunity" which were designed for earlier studies (Polvani et al., 2020; England et al., 2016) to study the effect of three distinct forcing agents on the Antarctic SMB. It should be noted that our approach assumes that the SMB responses to different forcings are additive and thus that the effects of nonlinear interactions between forcings can be ignored (Levermann et al., 2020).

Throughout the article, $\Delta$ represents the response of the climate system to the forcings, which is defined as the difference between the 1990-2005 period in each ensemble member and the 1940-1955 period in the corresponding member of the LENS. Thus, the response in LENS accounts for the effects of all historical forcing agents (hereafter referred to as All). We choose the 1990-2005 and 1940-1955 periods in order to examine the SMB response to historical forcing during the second half of the 20th century, when the entire response to ODS/ozone forcing occurs.

\section{The role of ozone vs. ODS in increasing the annual mean Antarctic SMB}

We start by quantifying the contribution of each forcing agent to the Antarctic annual mean $\triangle \mathrm{SMB}$ (Fig. 1a). Recall that while stratospheric ozone impacts the troposphere, primarily, by shifting the eddy-driven jet towards the South Pole in summer, the impact of ODS and tropospheric ozone is primarily a warming of the surface temperatures. We focus first on the annual mean response, as it is the most relevant for changes in sea-level rise. In the All ensemble the annual mean SMB increases by $191.6 \mathrm{Gt} \mathrm{yr}^{-1}$ over the second half of the 20th century (red bar), and ODS and stratospheric ozone make comparable contributions to the annual mean Antarctic SMB increase. Validating the results of Previdi and Polvani (2017) with a different model, we find that the increased emissions of ODSs account for $20 \%$ (38.4 $\mathrm{Gt} \mathrm{yr}^{-1}$ ) of the annual mean SMB increase (blue bar); stratospheric ozone depletion accounts for $24.2 \%\left(46.4 \mathrm{Gt} \mathrm{yr}^{-1}\right)$ of the annual mean SMB increase (green bar). Tropospheric ozone, on the other hand, shows a statistically insignificant contribution of only $12.7 \%\left(24.5 \mathrm{Gt} \mathrm{yr}^{-1}\right)$; increases in tropospheric 



Figure 1. Antarctic SMB response to second half of the 20th century forcing ( $\triangle \mathrm{SMB}$ ) in (a) annual mean, (b) DJF and (c) JJA. Red bars show the response in the full forcing ensemble mean (All). The blue, green and purple bars show the contributions of ODSs, stratospheric ozone $\left(\mathrm{O} 3_{\text {strat }}\right)$, and tropospheric ozone $\left(\mathrm{O} 3_{\text {trop }}\right)$ to the SMB response, respectively. Error bars represent the $95 \%$ confidence interval.

(a)
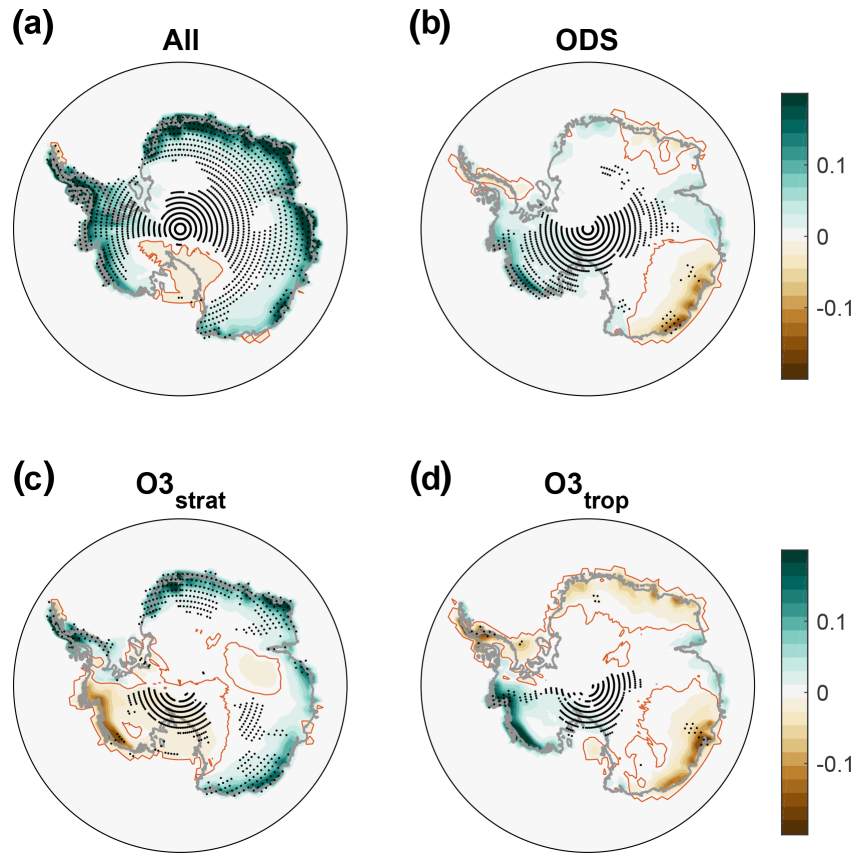

Figure 2. (a) Annual mean Antarctic SMB response to second half of the 20th century forcing $\left(\triangle \mathrm{SMB}, \mathrm{Gt} \mathrm{yr}^{-1}\right)$ in the full forcing ensemble mean (All). Panels (b-d) show the contributions of ODSs, stratospheric ozone $\left(\mathrm{O} 3_{\text {strat }}\right)$ and tropospheric ozone $\left(\mathrm{O} 3_{\text {trop }}\right)$ to the SMB response, respectively. Solid red lines mark the zero line. The small black dots show where the response is statistically significant at the $95 \%$ confidence level.

ozone are associated with air pollution and thus are mostly concentrated in the Northern Hemisphere. Thus, ODS and stratospheric ozone together account for $\sim 44 \%$ of the annual mean Antarctic SMB increase over the period of interest; the other $\sim 56 \%$ of the increase is caused by other forcings dominated by increases in $\mathrm{CO}_{2}$.
To further investigate the effects of ODSs and ozone depletion on the annual mean SMB, we next examine the spatial pattern of $\triangle \mathrm{SMB}$ (Fig. 2). In the All ensemble the SMB increase mostly occurs on the Antarctic coastline and over nearly all longitudes (green colors in Fig. 2a). While ODS (Fig. 2b) and tropospheric ozone (Fig. 2d) mostly increase the SMB over West Antarctica, stratospheric ozone increases it over East Antarctica and the Antarctic Peninsula (Fig. 2c). Thus, while ODS and stratospheric ozone have comparable impacts on the annual mean area-integrated $\triangle$ SMB (Fig. 1), it is the stratospheric ozone that is mostly responsible for the circumpolar increase of the SMB over the second half of the 20th century (Lenaerts et al., 2018).

Being powerful greenhouse gases, ODSs increase the SMB by warming and moistening the Antarctic atmosphere, thus allowing for more snowfall (Previdi and Polvani, 2017). However, the reason for the SMB increase due to stratospheric ozone is less clear, and thus we next elucidate the underlying mechanism. Given the strong seasonal signal of ozone depletion, one would expect that its effects on the SMB would peak during austral summer (DecemberFebruary, DJF); the ozone hole itself initially develops during spring, but its tropospheric impacts are delayed until summer (Previdi and Polvani, 2014). Figure $1 \mathrm{~b}$ and c show $\triangle \mathrm{SMB}$ during DJF and June-August (JJA). Indeed in the All ensemble (red bars) the largest increase in SMB of $295.5 \mathrm{Gt} \mathrm{yr}^{-1}$ occurs in DJF, compared with an increase of $124.1 \mathrm{Gt} \mathrm{yr}^{-1}$ in JJA. Unlike the annual mean case, in DJF stratospheric ozone alone accounts for the majority $(63.2 \%)$ of the total SMB increase and is more important than $\mathrm{CO}_{2}$. In comparison, ODS (blue bar) and tropospheric ozone (purple bar) have only minor effects on the DJF $\triangle \mathrm{SMB}$. 

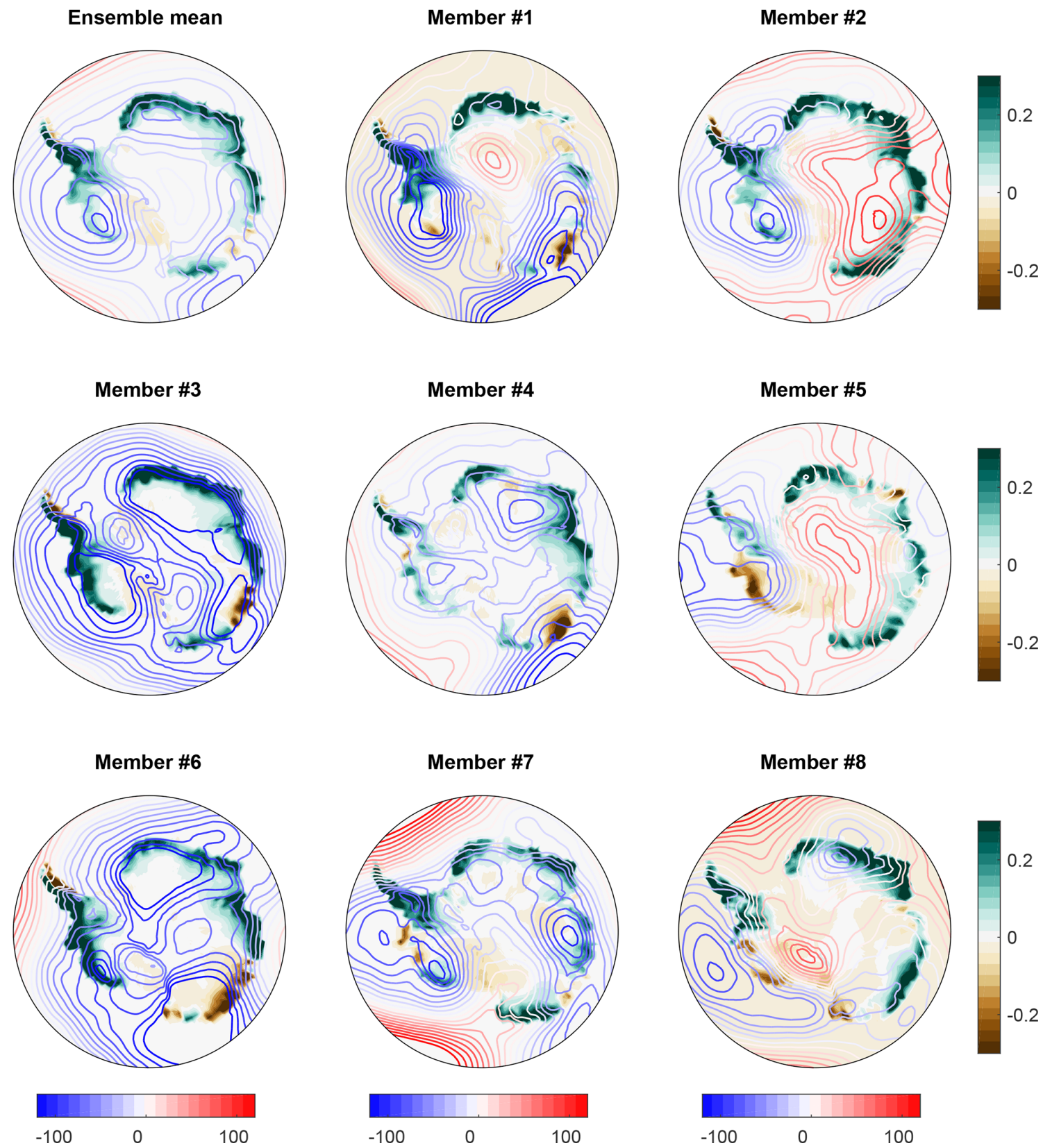

Figure 3. The difference in DJF Antarctic SMB (shading, Gt yr ${ }^{-1}$ ) and $500 \mathrm{hPa}$ geopotential height (contours, $\mathrm{m}^{2} \mathrm{~s}^{-2}$ ) between the full forcing ensemble (All) and the fixed stratospheric and tropospheric ozone ensemble (Fix-O3), averaged over the period 1986-2005.

\section{Elucidating the effects of stratospheric ozone on Antarctic SMB}

In this section we explore the mechanism by which ozone depletion increases the Antarctic SMB, focusing our analysis on the DJF season when the ozone signal is strongest. Recently, Lenaerts et al. (2018) suggested that ozone depletion acts to increase, across most longitudes, the meridional geopotential height gradient at $500 \mathrm{hPa}$ (associated with the zonal geostrophic wind), which they claimed was responsible for the circumpolar increase in DJF Antarctic SMB. This conclusion was based on the ensemble mean difference between the same full forcing (All) and Fix-O3 ensembles that are considered in the current study. To examine the robustness of that conclusion, we follow Lenaerts et al. (2018) and show in Fig. 3 the difference in $500 \mathrm{hPa}$ geopotential height (contours) and SMB (colors) between the All and the Fix-O3 experiments over the period 1986-2005 for each of the eight different ensemble members and for the ensemble mean.

As in Lenaerts et al. (2018) (cf. their Fig. 2), the ensemble mean indeed shows an increase in the meridional geopoten- 


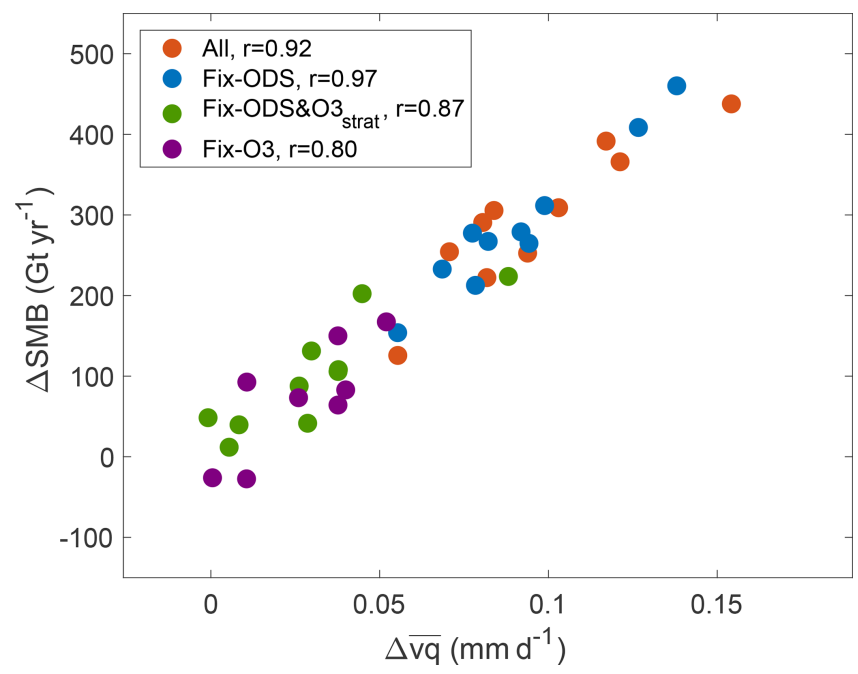

Figure 4. The response over the second half of the 20th century forcing of the DJF SMB $(\triangle \mathrm{SMB})$ as a function of the meridional moisture flux convergence $(\Delta \overline{v q})$ in the full forcing ensemble (All, red), fixed ODS ensemble (Fix-ODS, blue), fixed ODS and stratospheric ozone ensemble (Fix-ODS\&O $3_{\text {strat }}$, green), and fixed stratospheric and tropospheric ozone ensemble (Fix-O3, purple). Correlations appear in the upper left corner.

tial height gradient and SMB across most longitudes. However, while all members show an increase in SMB around the Antarctic continent, only half of the members (\# 3, 4, 6 and 7) show a circumpolar increase in the meridional geopotential height gradient. This suggests that changes in the spatial patterns of the zonal geostrophic wind at $500 \mathrm{hPa}$ are not robust across ensemble members. In any case, it is changes in the meridional convergence of moisture flux - and not changes in the mean zonal flow - that directly affect the zonal mean SMB (as shown below). We examine these meridional moisture flux changes next.

Changes in the surface precipitation minus evaporation ( $P-E$; equivalent to the SMB over Antarctica) can be analyzed using the zonal mean vertically integrated moisture equation (e.g., Trenberth and Guillemot, 1995; Seager et al., 2010):

$$
\begin{aligned}
& \Delta(\bar{P}(\phi)-\bar{E}(\phi))=-\frac{1}{g a \cos \phi} \\
& \frac{\partial}{\partial \phi}\left\{\int_{0}^{p_{\mathrm{s}}}\left([\bar{v}] \Delta \bar{q}+[\bar{q}] \Delta \bar{v}+\Delta \overline{v^{\prime} q^{\prime}}\right) \cos \phi \mathrm{d} p\right\},
\end{aligned}
$$

where the overbar represents zonal and DJF means, $g$ is gravity, $a$ is Earth's radius, $\phi$ is latitude, $p_{\mathrm{s}}$ is surface pressure, $v$ is the meridional velocity, $q$ is specific humidity, square brackets represent time mean calculated across the combined 1990-2005 and 1940-1955 periods, and the prime symbol represents deviation from zonal and monthly mean (i.e., transient and stationary eddies). The first term on the right-hand side of Eq. (1) accounts for changes in the mean moisture $(\bar{v} \Delta \bar{q})$, the second for the changes in meridional velocity $(\bar{q} \Delta \bar{v})$, and the third term accounts for changes in eddy moisture flux $\left(\Delta \overline{v^{\prime} q^{\prime}}\right)$. The convergence of each term on the righthand side is calculated over all latitudes. Note that $\bar{P}-\bar{E}$ is not identical to SMB (zonal mean $P-E$ vs. area integrated $P-E$ over only the Antarctic continent), as it accounts for processes that occur over the ocean (subantarctic regions account for a large portion of the Southern Ocean storms). To minimize this difference here, we average each term in Eq. (1) between 65 and $90^{\circ} \mathrm{S}$ to account for changes in $\bar{P}-\bar{E}$ mostly over the Antarctic continent. As a result, while changes in the total meridional moisture flux convergence $(\Delta \overline{v q}$, i.e., the sum of the terms on the right-hand side in Eq. 1) are larger in magnitude than $\triangle \mathrm{SMB}$, they are highly correlated with $\triangle \mathrm{SMB}$ as one can see in Fig. $4(r=0.92$ in All, $r=0.97$ in Fix-ODS, $r=0.87$ in Fix-ODS\&O3 $3_{\text {strat }}$ and $r=0.80$ in Fix-O3). The strong correlation between $\Delta \overline{v q}$ and $\triangle \mathrm{SMB}$ suggests that the zonal mean moisture budget (i.e., Eq. 1) can provide meaningful insight into the physical processes driving Antarctic SMB changes $(\bar{P}-\bar{E}$ processes over the ocean are linearly related to $\bar{P}-\bar{E}$ processes over land).

Figure 5 shows the contribution of each term in Eq. (1) to changes in DJF Antarctic $\bar{P}-\bar{E}$. First we focus on the response to all forcings (red bars). Moisture changes in DJF have only a minor effect on $\Delta(\bar{P}-\bar{E})(-0.03 \times$ $10^{-2} \mathrm{~mm} \mathrm{~d}^{-1}$; red bar in Fig. 5a), in contrast to changes in the mean meridional velocity $\left(4 \times 10^{-2} \mathrm{~mm} \mathrm{~d}^{-1}\right.$; Fig. $\left.5 \mathrm{~b}\right)$ and eddy moisture flux $\left(5.6 \times 10^{-2} \mathrm{~mm} \mathrm{~d}^{-1}\right.$; Fig. $\left.5 \mathrm{c}\right)$, which have a comparatively large effect. Second, similar to DJF $\triangle$ SMB (Fig. 1b), ODS (blue bars) and tropospheric ozone (purple bars) have minor effects on $\Delta(\bar{P}-\bar{E})$, in contrast to stratospheric ozone, which has a relatively large effect (green bars). Specifically, ozone depletion is found to account for $73.3 \%\left(2.9 \times 10^{-2} \mathrm{~mm} \mathrm{~d}^{-1}\right)$ and $54.9 \%\left(3.1 \times 10^{-2} \mathrm{~mm} \mathrm{~d}^{-1}\right)$ of the mean meridional velocity and eddy moisture flux contributions to the total in DJF, respectively. This corroborates the results of previous studies that showed the important and increasing role of eddies, driven by ozone depletion, in converging more moisture into the Antarctic (Papritz et al., 2014; Grieger et al., 2018) and thus, as shown here, increasing the SMB by enhancing snowfall.

Finally we ask the following: how does ozone depletion enhance the meridional flow? Previous studies have shown that by increasing the meridional temperature gradient aloft, ozone depletion acts to enhance the mean zonal wind on the poleward flank of the jet (e.g., Polvani et al., 2011b). This enhanced zonal wind is not confined to the upper levels but reaches all the way to the surface. Figure 6 shows the response in DJF mean zonal wind $(\Delta \bar{u})$ to the various forcings. In the historical (All) integrations, the mean zonal wind intensifies over the poleward flank of the jet (panel a), and this response is driven almost entirely by stratospheric ozone depletion (Fig. 6c). 

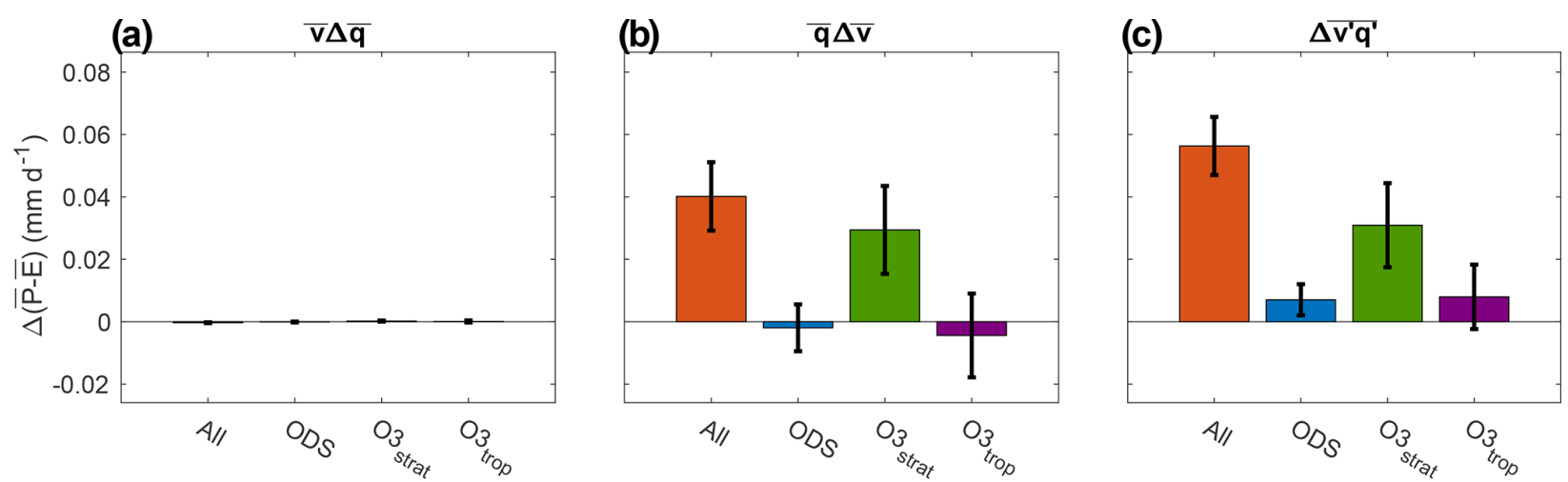

Figure 5. The contributions to the increase in DJF Antarctic $\bar{P}-\bar{E}, \Delta(\bar{P}-\bar{E})$, arising from changes in (a) mean moisture $(\bar{v} \Delta \bar{q}),(\mathbf{b})$ mean meridional circulation $(\bar{q} \Delta \bar{v})$ and (c) eddy moisture flux $\left(\Delta \overline{v^{\prime} q^{\prime}}\right)$. Red bars show the response in the full forcing ensemble mean. The blue, green and purple bars show the contributions of ODSs, stratospheric ozone $\left(\mathrm{O} 3_{\text {strat }}\right)$ and tropospheric ozone $\left(\mathrm{O} 3_{\text {trop }}\right)$ to the $P-E$ response, respectively. Error bars represent the $95 \%$ confidence interval.
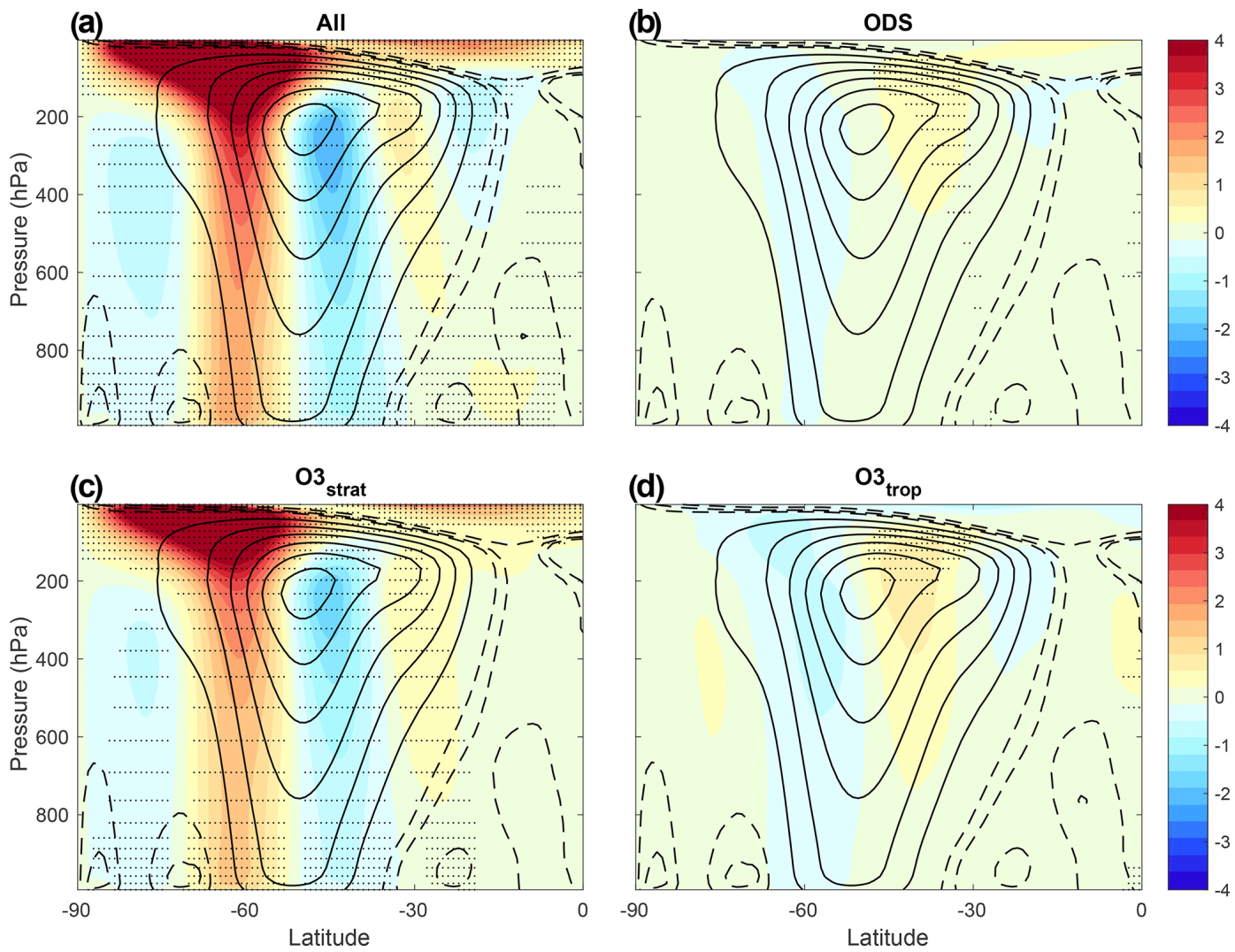

Figure 6. (a) The response over the second half of the 20th century forcing of the DJF zonal mean zonal wind $\left(\Delta \bar{u}\right.$, $\left.\mathrm{m} \mathrm{s}^{-1}\right)$ in the "All" forcing ensemble mean. Panels (b-d) show the contributions of ODSs, stratospheric ozone (O3 $\left.3_{\text {strat }}\right)$ and tropospheric ozone $\left(\mathrm{O} 3_{\text {trop }}\right)$ to $\Delta \bar{u}$, respectively. Contours show the zonal mean zonal wind in the 1940-1955 period. The small black dots show where the response is statistically significant at the $95 \%$ confidence level.

Do the changes in the mean zonal wind due to ozone depletion imply an increase in the meridional flow? In the lower troposphere at midlatitudes to high latitudes the frictional force on the zonal wind balances the Coriolis force on the meridional flow, $r \bar{u} \approx f \bar{v}$, where $r$ is a drag constant and $f$ is the Coriolis parameter (cf. p. 480 in Vallis, 2006). Note that eddy momentum fluxes do not appear in this balance as they are concentrated in the upper troposphere. This balance thus provides a link between ozone depletion and the meridional flow: the enhanced zonal wind at lower levels due to ozone 


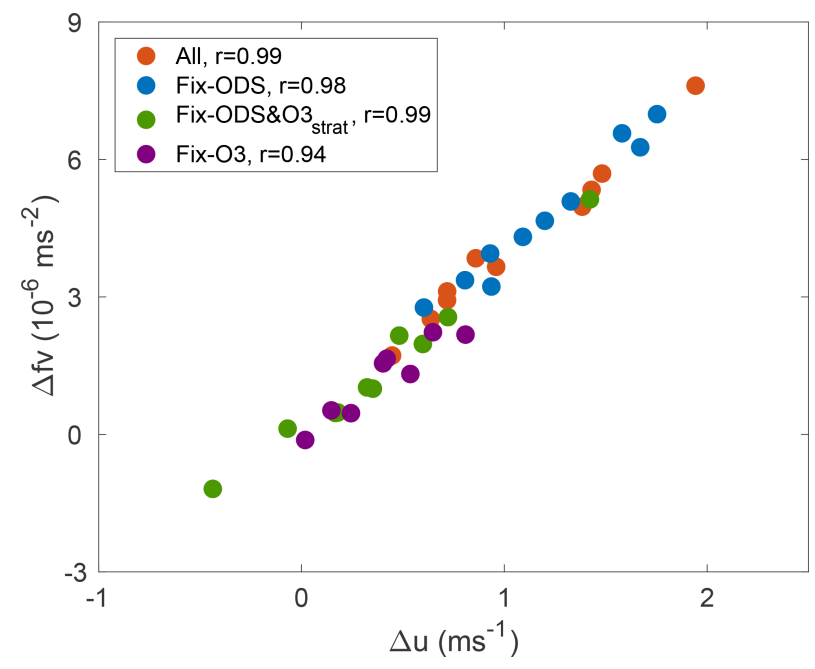

Figure 7. The response over the second half of the 20th century forcing of the DJF lower troposphere midlatitude to high-latitude Coriolis force on the meridional flow $(\Delta f v)$ as a function of the mean zonal wind $(\Delta u)$ in the full forcing ensemble (All, red), fixed ODS ensemble (Fix-ODS, blue), fixed ODS and stratospheric ozone ensemble (Fix-ODS\&O3 $3_{\text {strat }}$, green), and fixed stratospheric and tropospheric ozone ensemble (Fix-O3, purple). Correlations appear in the upper left corner.

depletion must be accompanied by an increase in the meridional wind as well. To demonstrate this balance, Fig. 7 shows the correlation between the DJF $\Delta f \bar{v}$ and $\Delta \bar{u}$ averaged over the lower troposphere ( $600 \mathrm{hPa}$ to surface) and over midlatitudes to high latitudes $\left(50-70^{\circ} \mathrm{S}\right)$ across the four ensembles. Changes in $f \bar{v}$ are very highly correlated with changes in $\bar{u}$, with $r=0.99$ in the All ensemble (red dots), $r=0.98$ for Fix-ODS (blue dots), $r=0.99$ for Fix-ODS\&O3 $3_{\text {strat }}$ (green dots) and $r=0.94$ for Fix-O3 (purple dots). Not only is there an excellent correlation between $\Delta f \bar{v}$ and $\Delta \bar{u}$, but ensembles with ozone depletion (All and Fix-ODS) show a larger increase in the mean zonal and meridional winds, in contrast to ensembles with fixed stratospheric ozone (Fix-ODS\&O3 $3_{\text {strat }}$ and Fix-O3). Thus, the enhanced meridional flow in the All ensemble and the associated increase in $\bar{P}-\bar{E}$ are largely due to the depletion of stratospheric ozone.

Changes in the mean zonal wind not only explain the increase in the mean meridional wind but can be directly linked to the increase in the eddy moisture flux. Midlatitude eddies are driven by baroclinic instability (which arises from the vertical shear of the zonal wind and the accompanying meridional temperature gradient); thus the stronger increase of the midlatitude to high-latitude $\left(50-70^{\circ} \mathrm{S}\right)$ mean zonal wind due to ozone depletion at upper levels relative to lower levels (i.e., an increase in the vertical shear; Fig. 6) suggests a strengthening of the eddies. However, during summer, the weak meridional temperature gradient might be insufficient to excite baroclinic eddies, and thus barotropic instability (which stems from the mean relative vorticity gradient, $u_{y} y$, where the $y$ subscript represents the meridional derivative) might also be a driver of the midlatitude eddies.

To examine which instability drives the increase in eddy moisture flux, in Fig. 8 we show the correlation between the vertically integrated $\Delta \overline{v^{\prime} q^{\prime}}$ (the eddy moisture flux) and $\Delta \overline{u_{\mathrm{z}}}$ (the vertical shear of the zonal wind, panel a) and the vertically averaged (through the entire atmosphere) $\Delta \overline{u_{y} y}$ (the curvature of the zonal winds, which is associated with barotropic instability, panel b). For simplicity, we define $\overline{u_{z}}$ as the zonal wind difference between upper $(300-500 \mathrm{hPa})$ and lower $(600-850 \mathrm{hPa})$ levels. All variables are averaged over midlatitudes to high latitudes $\left(50-70^{\circ} \mathrm{S}\right)$. We use here the absolute value of $\overline{v^{\prime} q^{\prime}}$ so that the positive values of $\Delta \overline{v^{\prime} q^{\prime}}$ indicate strengthening of the eddy moisture flux onto the Antarctic continent.

As seen in Fig. 8, $\Delta \overline{v^{\prime} q^{\prime}}$ has a modest correlation with $\Delta \overline{u_{\mathrm{z}}}$ across most ensembles $(r=0.50$ in All, $r=0.60$ in Fix-ODS, $r=0.71$ in Fix-ODS\&O3 $3_{\text {strat }}$ and $r=0.12$ in FixO3). More importantly, ensembles with ozone depletion (red and blue dots) do not show a significantly larger increase in $\overline{u_{\mathrm{Z}}}$ relative to ensembles with fixed stratospheric ozone (purple and green dots): ozone depletion thus has a weak impact on DJF $\overline{u_{\mathrm{z}}}$. In contrast, $\Delta \overline{v^{\prime} q^{\prime}}$ has a higher correlation with $\Delta \overline{u_{y} y}$ across most ensembles $(r=0.80$ in All, $r=0.77$ in Fix-ODS, $r=0.75$ in Fix-ODS\&O3 $3_{\text {strat }}$ and $r=-0.08$ in Fix-O3), and ensembles with ozone depletion (red and blue dots) do show a significant increase in $\overline{u_{y} y}$ relative to ensembles with fixed stratospheric ozone (purple and green dots). This analysis suggests that increased barotropic instability is the primary mechanism via which ozone depletion enhances the eddy-moisture flux, resulting in a larger Antarctic SMB over the second half of the 20th century.

\section{Conclusions}

Two recent studies have suggested that increasing ozonedepleting substances (ODSs) and the accompanying loss of stratospheric ozone have caused a substantial fraction of the increase in Antarctic surface mass balance over the second half of the 20th century. Neither study, however, cleanly separated these forcings. We here quantified the separate contribution of these forcing agents in increasing the Antarctic $\mathrm{SMB}$, using fixed-forcing ensembles of model simulations. Our results show that ODS and stratospheric ozone have had comparable effects on the annual mean Antarctic SMB; together they account for $\sim 40 \%$ of the SMB increase over the second half of the 20th century. The effects of stratospheric ozone are especially pronounced during austral summer, when they account for $\sim 60 \%$ of the SMB increase.

We have also shown that ozone depletion affects the SMB by enhancing the meridional circulation (mean and eddies), thus converging more water vapor over the Antarctic continent and leading to increases in snowfall. The enhanced meridional flow is linked to ozone depletion through changes 

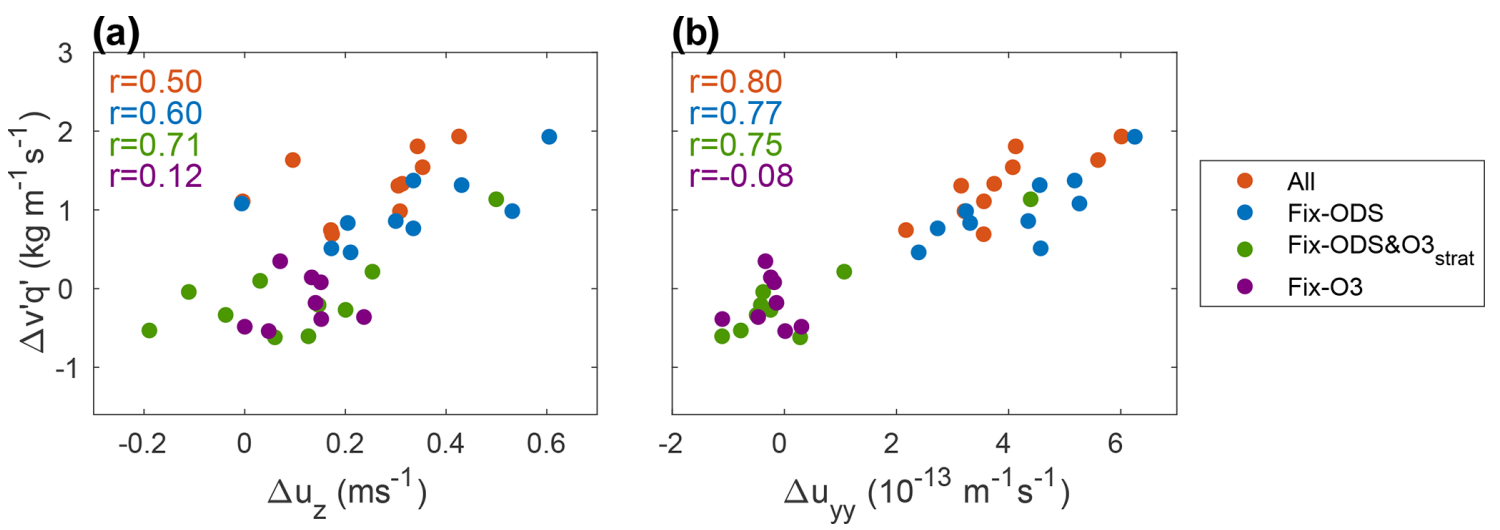

Figure 8. The response over the second half of the 20th century forcing of the DJF midlatitude to high-latitude eddy moisture flux $\left(\Delta \overline{v^{\prime} q^{\prime}}\right)$ as a function of (a) the vertical shear of the zonal wind $\left(\Delta u_{z}\right)$ and (b) the meridional gradient of the mean relative vorticity $\left(\Delta u_{y} y\right)$ in the full forcing ensemble (All, red), fixed ODS ensemble (Fix-ODS, blue), fixed ODS and stratospheric ozone ensemble (Fix-ODS\&O3 $3_{\text {strat }}$, green), and fixed stratospheric and tropospheric ozone ensemble (Fix-O3, purple). Correlations appear in the upper left corner of each panel.

in the mean zonal wind. Specifically, in the lower troposphere, a stronger mean zonal wind at midlatitudes to high latitudes is balanced by a stronger mean meridional wind. Additionally, increases in the meridional gradient of the zonal mean relative vorticity, due to ozone-induced zonal wind changes, enhances barotropic instability and leads to increases in meridional eddy moisture fluxes.

Our results have confirmed that ODSs and the accompanying depletion of stratospheric ozone have substantially contributed to the recent increases in Antarctic SMB; therefore, the phase-out of ODSs by the Montreal Protocol, and the accompanying recovery of stratospheric ozone, will act to decrease the SMB over the next several decades. The effect of ODS reduction and ozone recovery on the SMB will thus oppose the effect of increasing greenhouse gases, particularly during austral summer. This has implications for the emergence/identification of SMB increases in observations: not only could this emergence be delayed (or masked) by natural variability (Previdi and Polvani, 2016), but it will also be delayed as a consequence of the Montreal Protocol (Polvani et al., 2011a; Barnes et al., 2014).

Code and data availability. Data and codes are available upon request from Rei Chemke (rei.chemke@weizmann.ac.il).

Author contributions. RC analyzed the data, MRE conducted the runs, and together with MP and LMP discussed and wrote the manuscript.

Competing interests. The authors declare that they have no conflict of interest.
Acknowledgements. We acknowledge the CESM Large Ensemble Community Project and supercomputing resources provided by NSF/CISL/Yellowstone.

Financial support. This research has been supported by the National Science Foundation to Columbia University (grant no. OPP1745029).

Review statement. This paper was edited by Joel Savarino and reviewed by Ryan Fogt and one anonymous referee.

\section{References}

Agosta, C., Amory, C., Kittel, C., Orsi, A., Favier, V., Gallée, H., van den Broeke, M. R., Lenaerts, J. T. M., van Wessem, J. M., van de Berg, W. J., and Fettweis, X.: Estimation of the Antarctic surface mass balance using the regional climate model MAR (19792015) and identification of dominant processes, The Cryosphere, 13, 281-296, https://doi.org/10.5194/tc-13-281-2019, 2019.

Barnes, E. A., Barnes, N. W., and Polvani, L. M.: Delayed Southern Hemisphere Climate Change Induced by Stratospheric Ozone Recovery, as Projected by the CMIP5 Models, J. Climate, 27, 852-867, 2014.

Cataldo, M., Evangelista, H., Simões, J. C., Godoi, R. H. M., Simmonds, I., Hollanda, M. H., Wainer, I., Aquino, F., and Van Grieken, R.: Mineral dust variability in central West Antarctica associated with ozone depletion, Atmos. Chem. Phys., 13, 21652175, https://doi.org/10.5194/acp-13-2165-2013, 2013.

England, M. R., Polvani, L. M., Smith, K. L., Landrum, L., and Holland, M. M.: Robust response of the Amundsen Sea Low to stratospheric ozone depletion, Geophys. Res. Lett., 43, 82078213, 2016.

Fretwell, P., Pritchard, H. D., Vaughan, D. G., Bamber, J. L., Barrand, N. E., Bell, R., Bianchi, C., Bingham, R. G., Blankenship, D. D., Casassa, G., Catania, G., Callens, D., Conway, H., 
Cook, A. J., Corr, H. F. J., Damaske, D., Damm, V., Ferraccioli, F., Forsberg, R., Fujita, S., Gim, Y., Gogineni, P., Griggs, J. A., Hindmarsh, R. C. A., Holmlund, P., Holt, J. W., Jacobel, R. W., Jenkins, A., Jokat, W., Jordan, T., King, E. C., Kohler, J., Krabill, W., Riger-Kusk, M., Langley, K. A., Leitchenkov, G., Leuschen, C., Luyendyk, B. P., Matsuoka, K., Mouginot, J., Nitsche, F. O., Nogi, Y., Nost, O. A., Popov, S. V., Rignot, E., Rippin, D. M., Rivera, A., Roberts, J., Ross, N., Siegert, M. J., Smith, A. M., Steinhage, D., Studinger, M., Sun, B., Tinto, B. K., Welch, B. C., Wilson, D., Young, D. A., Xiangbin, C., and Zirizzotti, A.: Bedmap2: improved ice bed, surface and thickness datasets for Antarctica, The Cryosphere, 7, 375-393, https://doi.org/10.5194/tc-7-375-2013, 2013.

Frezzotti, M., Scarchilli, C., Becagli, S., Proposito, M., and Urbini, S.: A synthesis of the Antarctic surface mass balance during the last $800 \mathrm{yr}$, The Cryosphere, 7, 303-319, https://doi.org/10.5194/tc-7-303-2013, 2013.

Frieler, K., Clark, P. U., He, F., Buizert, C., Reese, R., Ligtenberg, S. R. M., van den Broeke, M. R., Winkelmann, R., and Levermann, A.: Consistent evidence of increasing Antarctic accumulation with warming, Nat. Clim. Change, 5, 348-352, 2015.

Golledge, N. R.: Long-term projections of sea-level rise from ice sheets, WIREs Clim Change, 11, e634, https://doi.org/10.1002/wcc.634, 2020.

Grieger, J., Leckebusch, G. C., Raible, C. C., Rudeva, I., and Simmonds, I.: Subantarctic cyclones identified by 14 tracking methods, and their role for moisture transports into the continent, Tellus A, 70, 1-18, https://doi.org/10.1080/16000870.2018.1454808, 2018.

Hurrell, J. W., Holland, M. M., Gent, P. R., Ghan, S., Kay, J. E., Kushner, P. J., Lamarque, J.-F., Large, W. G., Lawrence, D., Lindsay, K., Lipscomb, W. H., Long, M. C., Mahowald, N., Marsh, D. R., Neale, R. B., Rasch, P., Vavrus, S., Vertenstein, M., Bader, D., Collins, W. D., Hack, J. J., Kiehl, J., and Marshall, S.: The Community Earth System Model: A Framework for Collaborative Research, B. Am. Meteorol. Soc., 94, 1339-1360, 2013.

IPCC: Climate Change 2013: The Physical Science Basis. Contribution of Working Group I to the Fifth Assessment Report of the Intergovernmental Panel on Climate Change, edited by: Stocker, T. F., Qin, D., Plattner, G.-K., Tignor, M., Allen, S. K., Boschung, J., Nauels, A., Xia, Y., Bex, V., and Midgley, P. M., Cambridge University Press, Cambridge, United Kingdom and New York, NY, USA, 1535 pp., 2013.

Kay, J. E., Deser, C., Phillips, A., Mai, A., Hannay, C., Strand, G., Arblaster, J. M., Bates, S. C., Danabasoglu, G., Edwards, J., Holland, M., Kushner, P., Lamarque, J.-F., Lawrence, D., Lindsay, K., Middleton, A., Munoz, E., Neale, R., Oleson, K., Polvani, L., and Vertenstein, M.: The Community Earth System Model (CESM) Large Ensemble Project: A Community Resource for Studying Climate Change in the Presence of Internal Climate Variability, B. Am. Meteorol. Soc., 96, 1333-1349, 2015.

Krinner, G., Magand, O., Simmonds, I., Genthon, C., and Dufresne, J. L.: Simulated Antarctic precipitation and surface mass balance at the end of the twentieth and twenty-first centuries, Clim. Dynam., 28, 215-230, 2007.

Landrum, L. L., Holland, M. M., Raphael, M. N., and Polvani, L. M.: Stratospheric Ozone Depletion: An Unlikely Driver of the Regional Trends in Antarctic Sea Ice in Austral Fall in the Late Twentieth Century, Geophys. Res. Lett., 44, 11062-11070, 2017.
Lenaerts, J. T. M., van den Broeke, M. R., van de Berg, W. J., van Meijgaard, E., and Kuipers Munneke, P.: A new, high-resolution surface mass balance map of Antarctica (1979-2010) based on regional atmospheric climate modeling, Geophys. Res. Lett., 39, L04501, https://doi.org/10.1029/2011GL050713, 2012.

Lenaerts, J. T. M., Fyke, J., and Medley, B.: The Signature of Ozone Depletion in Recent Antarctic Precipitation Change: A Study With the Community Earth System Model, Geophys. Res. Lett., 45, 12931-12939, 2018.

Levermann, A., Winkelmann, R., Albrecht, T., Goelzer, H., Golledge, N. R., Greve, R., Huybrechts, P., Jordan, J., Leguy, G., Martin, D., Morlighem, M., Pattyn, F., Pollard, D., Quiquet, A., Rodehacke, C., Seroussi, H., Sutter, J., Zhang, T., Van Breedam, J., Calov, R., DeConto, R., Dumas, C., Garbe, J., Gudmundsson, G. H., Hoffman, M. J., Humbert, A., Kleiner, T., Lipscomb, W. H., Meinshausen, M., Ng, E., Nowicki, S. M. J., Perego, M., Price, S. F., Saito, F., Schlegel, N.-J., Sun, S., and van de Wal, R. S. W.: Projecting Antarctica's contribution to future sea level rise from basal ice shelf melt using linear response functions of 16 ice sheet models (LARMIP-2), Earth Syst. Dynam., 11, 3576, https://doi.org/10.5194/esd-11-35-2020, 2020.

Ligtenberg, S. R. M., van de Berg, W. J., van den Broeke, M. R., Rae, J. G. L., and van Meijgaard, E.: Future surface mass balance of the Antarctic ice sheet and its influence on sea level change, simulated by a regional atmospheric climate model, Clim. Dynam., 41, 867-884, 2013.

Monaghan, A. J., Bromwich, D. H., Fogt, R. L., Wang, S., Mayewski, P. A., Dixon, D. A., Ekaykin, A., Frezzotti, M., Goodwin, I., Isaksson, E., Kaspari, S. D., Morgan, V. I., Oerter, H., Van Ommen, T. D., Van der Veen, C. J., and Wen, J.: Insignificant Change in Antarctic Snowfall Since the International Geophysical Year, Science, 313, 827-831, 2006 .

Monaghan, A. J., Bromwich, D. H., and Wang, S.: Recent trends in Antarctic snow accumulation from Polar MM5 simulations, Philos. T. Roy. Soc. A, 364, 1683-1708, 2006 b.

Monaghan, A. J., Bromwich, D. H., and Schneider, D. P.: Twentieth century Antarctic air temperature and snowfall simulations by IPCC climate models, Geophys. Res. Lett., 35, L07502, https://doi.org/10.1029/2007GL032630, 2008.

Palerme, C., Genthon, C., Claud, C., Kay, J. E., Wood, N. B., and L'Ecuyer, T.: Evaluation of current and projected Antarctic precipitation in CMIP5 models, Clim. Dynam., 48, 225-239, 2017.

Papritz, L., Pfahl, S., Rudeva, I., Simmonds, I., Sodemann, H., and Wernli, H.: The Role of Extratropical Cyclones and Fronts for Southern Ocean Freshwater Fluxes, J. Climate, 27, 6205-6224, 2014.

Polvani, L. M., Previdi, M., and Deser, C.: Large cancellation, due to ozone recovery, of future Southern Hemisphere atmospheric circulation trends, Geophys. Res. Lett., 38, L04707, https://doi.org/10.1029/2011GL046712, 2011a.

Polvani, L. M., Waugh, D. W., Correa, G. J. P., and Son, S. W.: Stratospheric Ozone Depletion: The Main Driver of TwentiethCentury Atmospheric Circulation Changes in the Southern Hemisphere, J. Climate, 24, 795-812, 2011b.

Polvani, L. M., Previdi, M., England, M. R., Chiodo, G., and Smith, K. L.: Substantial twentieth-century Arctic warming caused by ozone-depleting substances, Nat. Clim. Change, 10, 130-133, 2020 . 
Previdi, M. and Polvani, L. M.: Climate system response to stratospheric ozone depletion and recovery, Q. J. Roy. Meteor. Soc., 140, 2401-2419, 2014.

Previdi, M. and Polvani, L. M.: Anthropogenic impact on Antarctic surface mass balance, currently masked by natural variability, to emerge by mid-century, Env. Res. Lett., 11, 094001, https://doi.org/10.1088/1748-9326/11/9/094001, 2016.

Previdi, M. and Polvani, L. M.: Impact of the Montreal Protocol on Antarctic Surface Mass Balance and Implications for Global Sea Level Rise, J. Climate, 30, 7247-7253, 2017.

Rignot, E., Casassa, G., Gogineni, P., Krabill, W., Rivera, A., and Thomas, R.: Accelerated ice discharge from the Antarctic Peninsula following the collapse of Larsen B ice shelf, Geophys. Res. Lett., 31, L18401, https://doi.org/10.1029/2004GL020697, 2004.

Rignot, E., Mouginot, J., Scheuchl, B., van den Broeke, M., van Wessem, M. J., and Morlighem, M.: Four decades of Antarctic Ice Sheet mass balance from 1979-2017, P. Natl. Acad. Sci. USA, 116, 1095-1103, 2019.

Seager, R., Naik, N., and Vecchi, G. A.: Thermodynamic and Dynamic Mechanisms for Large-Scale Changes in the Hydrological Cycle in Response to Global Warming, J. Climate, 23, 46514668, 2010.

Shepherd, A., Ivins, E. R., Geruo, A., Barletta, V. R., Bentley, M. J., Bettadpur, S., Briggs, K. H., Bromwich, D. H., Forsberg, R., Galin, N., Horwath, M., Jacobs, S., Joughin, I., King, M. A., Lenaerts, J. T. M., Li, J., Ligtenberg, S. R. M., Luckman, A., Luthcke, S. B., McMillan, M., Meister, R., Milne, G., Mouginot, J., Muir, A., Nicolas, J. P., Paden, J., Payne, A. J., Pritchard, H., Rignot, E., Rott, H., Sørensen, L. S., Scambos, T. A., Scheuchl, B., Schrama, E. J. O., Smith, B., Sundal, A. V., van Angelen, J. H., van de Berg, W. J., van den Broeke, M. R., Vaughan, D. G., Velicogna, I., Wahr, J., Whitehouse, P. L., Wingham, D. J., Yi, D., Young, D., and Zwally, H. J.: A Reconciled Estimate of Ice-Sheet Mass Balance, Science, 338, 1183-1189, https://doi.org/10.1126/science.1228102, 2012.
Taylor, K. E., Stouffer, R. J., and Meehl, G. A.: An Overview of CMIP5 and the Experiment Design, B. Am. Meteorol. Soc., 93, 485-498, 2012.

Trenberth, K. E. and Guillemot, C. J.: Evaluation of the Global Atmospheric Moisture Budget as Seen from Analyses, J. Climate, 8, 2255-2280, 1995.

Uotila, P., Lynch, A. H., Cassano, J. J., and Cullather, R. I.: Changes in Antarctic net precipitation in the 21st century based on Intergovernmental Panel on Climate Change (IPCC) model scenarios, J. Geophys. Res., 112, D10107, 2007.

Vallis, G. K.: Atmospheric and Oceanic Fluid Dynamics, 1st edn., Cambridge University Press, Cambridge, UK, 770 pp., 2006.

Velicogna, I., Sutterley, T. C., and van den Broeke, M. R.: Regional acceleration in ice mass loss from Greenland and Antarctica using GRACE time-variable gravity data, Geophys. Res. Lett., 41, 8130-8137, 2014.

Wouters, B., Martin-Español, A., Helm, V., Flament, T., van Wessem, J. M., Ligtenberg, S. R. M., van den Broeke, M. R., and Bamber, J. L.: Dynamic thinning of glaciers on the Southern Antarctic Peninsula, Science, 348, 899-903, 2015. 